\title{
Aterosklerotik Hastalığın Primer Korumasında Aspirin Kullanımının Uygunluğu: ASSOS Çalışmasının Altgrup Analizi
}

\author{
The Appropriateness of Aspirin Use for Primary Prevention of \\ Atherosclerotic Disease: A Subgroup Analysis of the ASSOS Study
}

\author{
Oğuzhan ÇELİK${ }^{1}$, Cem ÇíL ${ }^{2}$ \\ ${ }^{1}$ Muğla Sıtkı Koçman Üniversitesi Tıp Fakültesi Kardiyoloji Anabilim Dalı, Muğla \\ ${ }^{2}$ Özel Level Hastanesi, Kardiyoloji Bölümü, Zonguldak
}

\begin{abstract}
$\ddot{\mathbf{O z}}$
Ülkemizde aspirin kardiyovasküler hastalıklardan korunma amacıyla en çok kullanılan ilaçlardan biridir. Ancak aspirinin primer korumada uygun endikasyon dahilinde kullanılıp kullanılmadığı yeterince araştırılmamıştır. Bu çalışmanın amacı, primer korumada aspirinin reçete dağılımını incelemek ve uluslararası kılavuzlara göre uygunluğunu araştırmaktır. The Appropriateness of Aspirin Use in Medical Outpatients: A Multicenter, Observational Study (ASSOS çalıșması) Türkiye'nin her bölgesinden ve 14 farklı şehirden 30 farklı kardiyoloji polikliniğinden alınan veriler ile sağlanan çok merkezli kesitsel bir çalışma şeklinde dizayn edilmiştir. Çalışmaya kardiyoloji polikliniğe başvuran 18 yaş üstü, son 30 gün içinde her ne sebeple olursa olsun düzenli olarak düşük doz aspirin $(75-100 \mathrm{mg}$ ) kullanan hastalar dahil edilmişsir. Çalışmamızda bu hastalardan sekonder koruma nedeniyle aspirin kullananlar çıkarılarak sadece primer koruma amaçlı aspirin kullanananlar değerlendirildi ve sonuçların primer korumada aspirin kullanımının 2016 European Society of Cardiology (ESC) ve 2019 American College of Cardiology/American Heart Association (ACC/AHA) kılavuzlarına göre uygunluk oranı araştırılmıştır. 2016 ESC kılavuzuna göre hastaların \%100'ünde, 2019 ACC/AHA kılavuzuna göre ise hastaların \%89'unda primer koruma için uygunsuz aspirin kullanımı tespit edildi. Ülkemizde gerek ESC kılavuzuna göre gerekse de ACC/AHA kılavuzuna göre primer korumada uygunsuz aspirin kullanımı sıktır.
\end{abstract}

Anahtar Kelimeler: Aspirin, Kılavuzlara Uygunluk, Primer Koruma

\section{Giriş}

Kardiyovasküler hastalıklar (KVH), günümüzde tüm ölümlerin yarısına yakınından sorumludur (1). Aspirin KVH'ların tedavisinde gerek mortalite gerekse de morbidite faydası bilinen en eski ve en güvenilir ilaçtır (2). Çok sayıda çalışma sekonder korumada aspirin kullanımını desteklerken, primer korumada aspirin kullanımının yeri hala tartışmalıdır (3). 2016 ESC k1lavuzu primer korumada aspirin kullanımını kısıtlı faydası ve artan kanama sıklığı nedeni ile önermezken, 2019 ACC/AHA k1lavuzu yalnızca 40 ila 70 yaş arasında olan, yüksek KVH riskli olup kanama riski düşük olan hastalara aspirin

\begin{tabular}{ll}
\hline $\begin{array}{l}\text { Oğuzhan ÇELIK } \\
\text { Cem ÇİL }\end{array}$ & $\begin{array}{l}\text { ORCID No } \\
\text { 0000-0001-7841-0227 } \\
\text { 0000-0003-2428-5170 }\end{array}$ \\
$\begin{array}{l}\text { Başvuru Tarihi / Received: } \\
\text { Kabul Tarihi / Accepted : }\end{array}$ \\
$\begin{array}{ll}\text { Adres / Correspondence : } & \text { Oğuzhan ÇELIK } \\
\text { Muğla Sitkı Koçman Üniversitesi Tıp Fakültesi Kardiyoloji } \\
\text { Anabilim Dalı, Muğla } \\
\text { e-posta / e-mail }\end{array}$ \\
\hline
\end{tabular}

\begin{abstract}
Aspirin is one of the most commonly used drugs to prevent cardiovascular diseases in our country. However, whether aspirin is used in primary prevention within the appropriate indication has not been adequately studied. The aim of this study is to investigate prescription distribution and appropriate use of aspirin in primary prevention according to international guidelines. The Appropriateness of Aspirin Use in Medical Outpatients: A Multicenter, Observational Study is from all regions of Turkey and provided data from 14 different cities in 30 different cardiology clinics. It has been designed as a multicenter, cross-sectional study. Patients over the age of 18, who applied to the cardiology outpatient clinic, and who regularly use low-dose aspirin $(75-100 \mathrm{mg}$ ) in the last 30 days for any reason, were included in the study. Patients, who use aspirin for secondary prevention, were excluded for this analysis and the appropriateness of aspirin use was evaluated according to the 2016 European Society of Cardiology (ESC) and 2019 American College of Cardiology/American Heart Association (ACC/AHA) guidelines. Inappropriate aspirin use for primary prevention was detected in 100\% of patients according to the 2016 ESC guidelines and in $89 \%$ of patients according to the 2019 ACC/AHA guidelines. In our country, inappropriate aspirin use is common in primary prevention according to the ESC guidelines and ACC/AHA guidelines.
\end{abstract}

Keywords: Aspirin, Compliance with the Guidelines, Primary Prevention

kullanımını önermektedir $(4,5)$ (Tablo 1). Dünya sağlık örgütü gelişmekte olan ülkelerde tüm ilaçların neredeyse yarısının uygunsuz olarak reçete edildiğini belirtmiştir (6). Çalışmamızda ülkemizde primer korumada aspirin kullanımının kılavuzlara göre uygunluğu araştırılmıştır.

\section{Gereç ve Yöntem}

ASSOS çalışması olarak adlandırılan çalışmamız çok merkezli, gözlemsel, kesitsel ve kohort çalışmasıdır (7). Muğla Sıtkı Koçman Üniversitesi Klinik Araştırmalar Etik Kurulu'ndan 01.03.2018 tarih ve 01/09 sayılı yazı ile izin alınmıştır. Kullanım endikasyonuna bakılmaksızın düzenli aspirin tedavisi alan tüm hastaları toplamak için tasarlanmıştır. Çalışma, hastanelerde çalışan kardiyologlar tarafindan gerçekleştirildi ve Türkiye'nin her bölgesinden 30 kardiyologdan veriler toplandı. Çalışmada herhangi bir teşhis veya tedavi prosedürü şart koşulmadi. 18 yaş ve üzeri, yazılı bilgilendirilmiş onam ile çalışmaya katılmak isteyen ve son 30 gün içinde herhangi bir sebeple düzenli düşük doz aspirin (75-100 mg) alan hastalar 
çalışmaya dahil edildi. Hamileler, 18 yaşın altındaki hastalar, zeka geriliği olanlar ve çalışmaya katılmak istemeyen hastalar veya yazilı kabul onamı vermeyen hastalar çalışma dışı bırakıldı. Bu altgrup analizinde sekonder profilaksi için aspirin kullananlar çalışma dışı bırakıldı. Hastaların demografik özellikleri, tanıları, fizik muayene bulguları, kullanmakta oldukları ilaçları ve laboratuvar değerleri incelendi.

Tablo 1. K1lavuzların Önerileri

\begin{tabular}{|c|c|c|}
\hline Kılavuz & Öneri & $\begin{array}{c}\text { Kanıt } \\
\text { düzeyi }\end{array}$ \\
\hline \multirow{3}{*}{$\begin{array}{c}2019 \text { American } \\
\text { College of } \\
\text { Cardiology/American } \\
\text { Heart } \\
\text { Association } \\
\text { Guideline on } \\
\text { the Primary } \\
\text { Prevention of } \\
\text { Cardiovascular } \\
\text { Disease }\end{array}$} & 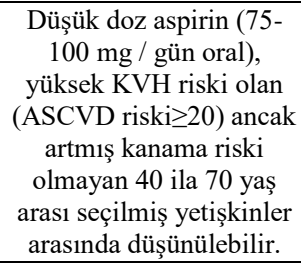 & $\mathrm{IIb}, \mathrm{A}$ \\
\hline & $\begin{array}{l}\text { Düşük doz aspirin (75- } \\
100 \mathrm{mg} \text { / gün oral), } 70 \\
\text { yaşın üzerindeki } \\
\text { yetişkinlerde KVH' in } \\
\text { primer koruması için } \\
\text { rutin olarak önerilmez. }\end{array}$ & $\begin{array}{c}\text { III, B- } \\
\text { R }\end{array}$ \\
\hline & $\begin{array}{l}\text { Düşük doz aspirin (75- } \\
100 \mathrm{mg} \text { / gün oral), } \\
\text { kanama riski yüksek olan } \\
\text { her yaştaki yetişkinlerde } \\
\text { KVH'ın primer koruması } \\
\text { için önerilmez. }\end{array}$ & $\begin{array}{l}\text { III, C- } \\
\text { LD }\end{array}$ \\
\hline $\begin{array}{l}\text { European Society of } \\
\text { Cardiology } 2016 \\
\text { Guidelines on } \\
\text { Cardiovascular } \\
\text { Disease Prevention in } \\
\text { Clinical Practice }\end{array}$ & $\begin{array}{l}\text { KVH' } 1 \text { olmayan } \\
\text { kişilerde aspirin } \\
\text { önerilmez }\end{array}$ & III, B \\
\hline
\end{tabular}

\section{Bulgular}

Türkiye çapında primer koruma amaçlı aspirin kullanan total 1132 hasta çalışmaya dahil edildi. Bu hastaların \%56'sı $(n=634)$ kadındı, ortalama yaş $61.79 \pm 11.90$ idi. Hastaların demografik özellikleri Tablo 2'de özetlenmiştir. Kanama risk değerlendirilmesi HASBLED skoruna göre değerlendirildi. 1132 primer koruma hastasından 40 yaş altı ve 70 yaş üstü hastalar ACC/AHA kılavuzuna uygun olarak değerlendirilmeye alınmad1. Geri kalan 834 hasta primer koruma da uygunluk açısından değerlendirildi. ASCVD yüksek risk grubu olarak ASCVD risk cetveline $\% 20$ ve üzeri baz alındı (Tablo 3). Bunlardan 244'ü (\%29.3) düşük riskli (ASCVD<\%5), 120'si (\%14.4) borderline riskli (ASCVD \%5-7.5), 345'i (\%41.4) orta riskli (ASCVD \%7.5-20) ve 125'i (\%14.9) yüksek riskli gruba (ASCVD risk skoru $\geq \%$ 20) uymaktaydı. Yüksek riskli grubun ( $\geq \% 20$ ASCVD riskli) ve düşük kanama riski (HASBLED $<3$ ) olan hasta sayısı 94 (\%11.3) iken, yüksek riskli ( $\geq \% 20$ ASCVD riskli) ve yüksek kanama (HASBLED $\geq 3$ ) olan hastaların sayısı 31 (\%3.7) idi (Tablo 4). Bu nedenle, 2019 ACC/AHA göre 834 hastanın primer koruma için sadece 94'ü (\%11.3) uygun aspirin kullanımı olarak kabul edildi.

Tablo 2. Çalışma hastalarının demografik özellikleri

\begin{tabular}{lcc}
\hline & $\begin{array}{c}\text { Hasta sayısı n } \\
(\mathbf{\%})\end{array}$ \\
\hline Kadın & $634(56.0)$ \\
Yaş, yıl (ortalama \pm SS) & $61.79 \pm 11.90$ \\
Sigara & $217(19.2)$ \\
VKİ, kg/m² (ortalama \pm SS) & $29.04 \pm 5.14$ \\
Alkol & $58(5.1)$ \\
Eğitim durumu & Okuma yazma yok & $210(18.6)$ \\
& İlkokul & $526(46.5)$ \\
& Ortaokul & $143(12.6)$ \\
& Lise & $178(15.7)$ \\
Yaşadığı yer & Üniversite & $75(6.6)$ \\
& Kirsal & $228(20.1)$ \\
Hipertansiyon & Şehir & $904(79.9)$ \\
Atriyal fibrilasyon & $848(74.9)$ \\
Kalp yetmezliği & $99(8.7)$ \\
Diyabetes mellitus & $99(8.7)$ \\
Hiperlipidemi & $313(27.7)$ \\
KOAH & $331(29.2)$ \\
\hline
\end{tabular}

Tablo 3. ASCVD 10 yıllık risk cetveli

\begin{tabular}{ll} 
Tablo 3. ASCVD 10 y1llk risk cetvel & \\
\hline $\mathbf{1 0}$ yillı ASCVD & (Atherosclerotic \\
Cardiovascular Disease) 2013 ACC/AHA Risk \\
Calculator
\end{tabular}

Tablo 4. Primer korumada 40-70 yaş aralığındaki hastaların ASCVD risk oranına göre aspirin kullanımının dağılımı

\begin{tabular}{|c|c|c|}
\hline \multicolumn{2}{|c|}{ ASCVD Risk Oranı } & $\begin{array}{c}\text { Hasta sayısı } \\
\text { n }(\%)\end{array}$ \\
\hline \multirow{3}{*}{\multicolumn{2}{|c|}{$\begin{array}{l}\text { Düşük KVH risk }(<\% 5) \\
\text { Borderline KVH risk }(\% 5-7.5) \\
\text { İntermediate KVH risk }(\% 7.5-20)\end{array}$}} & $244(29.3)$ \\
\hline & & $120(14.4)$ \\
\hline & & $345(41.4)$ \\
\hline \multirow[t]{2}{*}{ Yüksek KVH risk $(\geq \% 20)$} & HASBLED $\geq 3$ & $31(3.7)$ \\
\hline & HASBLED $<3$ & $94(11.3)$ \\
\hline
\end{tabular}

Primer koruma için aspirin kullanımının endikasyonu 2016 ESC ve 2019 ACC/AHA kılavuzlarına göre değerlendirildi $(4,5)$. Kanama risk değerlendirilmesi HASBLED skoruna göre tanımland. HASBLED skorunda hipertansiyon, anormal böbrek/karaciğer fonksiyonu (her biri bir puan), inme öyküsü, kanama öyküsü veya predispozanları, labil international normalized ratio (INR), 65 yaş üstü ve ilaç/alkol kullanımı (her biri 1 puan) olarak değerlendirildi (8). 0 puan düşük kanama riski, 1-2 puan orta kanama risk ve 3 puan ve üzeri yüksek kanama riski olarak tanımlandı. KVH için risk analizi 2019 ACC/AHA kılavunun önerdiği şekilde ASCVD (Atherosclerotic Cardiovascular Disease) 2013 Risk Calculator cetveline göre yapıldı (9). ASCVD risk skoru $<\% 5$ olanlar düşük risk, \%5-7.5 arası borderline risk, $\% 7.5-20$ aras1 intermediate risk, $\geq \% 20$ olanlar yüksek risk olarak kabul edildi. 
İstatistiksel değerlendirmede sürekli değişkenler ortalama \pm standard sapma ile gösterildi. Kategorik değişkenler frekans ve yüzde olarak gösterildi. İstatistiksel analiz Microsoft Excel programı ile yapild1.

\section{Tartışma}

Çalışmamız bize ülkemizde primer koruma için uygunsuz aspirin kullanımının oldukça fazla olduğunu göstermiştir. Sekonder korumada aspirin kullanımı kanıta dayalı tıp yaklaşımında ne kadar vazgeçilmez ve gerekli ise de primer korumadaki yeri kısıtlı ve çelişkilidir. Bu çelişkinin aslında dünyanın en önemli iki kılavuzuna da yansıdığı görülmektedir. Primer korumada aspirin kullanımına ilişkin Avrupa ve Amerika kılavuzları arasında farklı öneriler vardır. ESC kılavuzları, aspirinin primer koruma için kullanılmamasını ve KVH'nin klinik belirtileri olmayan hastaların aspirin almaması gerektiğini önermektedir (sınıf III, düzey A) (4). ACC/AHA kılavuzu, düşük doz aspirinin, sadece yüksek KVH riski taşıyan ancak artmış kanama riskine sahip olmayan (sınıf IIb, düzey A) 40 ila 70 yaşlarındaki kişilerde düşünülebileceğini tavsiye ederken, 70 yaşın üzerindeki hastalarda, 40 yaş altındaki hastalarda (sınıf III, düzey B) ve yüksek kanama riski olan her yaştaki hastalarda kullanılmasından kaçınılmasını önermektedir (sınıf III, düzey C) (5).

Antithrombotic Trialists' Collaboration meta-analizi, KVH açısından düşük riskli 95.000 hastalık altı primer koruma çalışmasını içermektedir (10). Analizinde görüldü ki primer koruma için aspirin alan hastalarda kardiyovasküler mortalitede önemli ölçüde azalma olmadı ayrıca majör gastrointestinal ve ekstrakraniyal kanamalar da dahil olmak üzere kanama riski önemli ölçüde arttı. Bununla birlikte, 2000 yilından sonra yayınlanan araştırmalardan elde edilen son veriler bize, aspirinin fatal veya non-fatal miyokard enfarktüsü, inme, kardiyovasküler ölüm veya tüm nedenlere bağlı ölüm riskini azaltmada beklendiği kadar etkili olmadığını göstermiştir (11).

Birçok çalışma, aspirin tedavisinin hem gereğinden fazla hem de yetersiz kullanıldığını göstermiştir $(12,13)$. Bunun nedeni, hastaların ilacın fayda sağlayacağına olan inanışı veya klinisyenlerin tercihleriyle ilişskili olabilir.

Ülkemizdeki uygunsuz aspirin kullanımına ilişkin veriler çok sınırlıdır, ancak Avrupa ve ABD tarafından yapılan çalışmalar daha önce primer korunma için aspirinin aşırı kullanıldığını belgelemiştir (14-16).

Çalışmamızda güncel kılavuzların tanımlarını kullandık ve uygunsuz aspirin kullanım sıklı̆̆ının ESC' ye göre \%100, ACC/AHA kılavuzlarına göre $\% 89$ olduğunu bulduk.

ASSOS çalışmasının sonuçları, randomize kontrollü çalışmaların ve uluslararası kılavuzların yakın zamanda güncellenmesine rağmen, ülkemizde primer korumada aspirinin aşırı kullanımını ortaya çıkardı.

Etik Kurul Onayı: Muğla Sitkı Koçman Üniversitesi Klinik Araştırmalar Etik Kurulu'ndan 01.03.2018 tarih ve 01/09 say1l yazı ile izin alınmıştır.

\section{Kaynaklar}

1. Benjamin EJ, Muntner P, Alonso A, et al. Heart Disease and Stroke Statistics-2019 Update: A Report From the American Heart Association. Circulation. 2019;139:56-528.

2. Montinari MR, Minelli S, De Caterina R. The first 3500 years of aspirin history from its roots. A concise summary. Vascul Pharmacol. 2019;113:1-8.

3. Berger JS, Brawn DL, Becker RC. Low-dose aspirin in patients with stable cardiovascular disease: a meta-analysis. Am J Med. 2008;121(1):43-9.

4. 2016 European Guidelines on cardiovascular disease prevention in clinical practice: The Sixth Joint Task Force of the European Society of Cardiology and Other Societies on Cardiovascular Disease Prevention in Clinical Practice (constituted by representatives of 10 societies and by invited experts)Developed with the special contribution of the European Association for Cardiovascular Prevention \& Rehabilitation (EACPR). Eur Heart J. 2016;37:2315-81.

5. Arnett DK, Blumenthal RS, Albert MA, et al. 2019 ACC/AHA guideline on the primary prevention of cardiovascular disease: a report of the American College of Cardiology/American Heart Association Task Force on Clinical Practice Guidelines. Circulation. 2019;140:596-646.

6. WHO Progress in the rational use of medicines. World Health Assembly Resolution, WHA60.16, World Health Organisation, Geneva (2007). http://apps.who.int/gb/ebwha/pdf_files/whassa_wha60rec1/e/reso-60-en.pdf p.71.

7. Çelik O, Çil C, Özlek Ö, et al. Design and rationale for the ASSOS study: Appropriateness of aspirin use in medical outpatients a multicenter and observational study. Anatol J Cardiol. 2018;20(6):354-62.

8. Shah RR, Pillai A, Omar A, et al. Utility of the HAS-BLED Score in Risk Stratifying Patients on Dual Antiplatelet Therapy Post 12 Months After Drug-Eluting Stent Placement. Catheter Cardiovasc Interv. 2017;89:99-103.

9. 2013 ACC/AHA guideline on the assessment of cardiovascular risk: a report of the American College of Cardiology/American Heart Association Task Force on Practice Guidelines. Circulation. 2014;129(2):49-73.

10. Antithrombotic Trialists' Collaboration. Collaborative metaanalysis of randomised trials of antiplatelet therapy for prevention of death, myocardial infarction, and stroke in high risk patients. BMJ. 2002;324(7329):71-86.

11. Seshasai SR, Wijesuriya S, Sivakumaran R, et al. Effect of aspirin on vascular and nonvascular outcomes: meta-analysis of randomized controlled trials. Arch Intern Med. 2012;172:209-16

12. Naderi SH, Bestwick JP, Wald DS. Adherence to drugs that prevent cardiovascular disease: a meta-analysis on 376,162 patients. Am J Med. 2012;125:882-7.

13. VanWormer JJ, Greenlee RT, McBride PE, et al. Aspirin for primary prevention of CVD: are the right people using it? J Fam Pract. 2012;61:525-32.

14. U.S. Preventive Services Task Force. Aspirin use for the primary prevention of cardiovascular disease and colorectal cancer: U.S. Preventive Services Task Force recommendation statement. Ann Intern Med. 2016;164:83645.

15. The Task Force on diabetes, pre-diabetes, and cardiovascular diseases of the European Society of Cardiology (ESC) and developed in collaboration with the European Association for 
the Study of Diabetes (EASD). Eur Heart J. 2013;34:303587.

16. American Heart Association Diabetes Committee of the Council on Lifestyle and Cardiometabolic Health, Council on Clinical Cardiology, Council on Cardiovascular and Stroke Nursing, Council on Cardiovascular Surgery and Anesthesia,
Council on Quality of Care and Outcomes Research, and the American Diabetes Association Update on Prevention of Cardiovascular Disease in Adults With Type 2 Diabetes Mellitus in Light of Recent Evidence: A Scientific Statement From the American Heart Association and the American Diabetes Association. Circulation. 2015;132:691-718. 